\section{Agricultural Aviation Group}

An Agricultural Aviation Group has recently been formed by the Royal Aeronautical Society. The aims of the Group are to further the use of aircraft in agriculture, forestry, pest control, fertilizing, seeding, chemical application and similar subjects and to provide facilities for those interested in such matters to meet and exchange ideas and information. The formation of the Agricultural Aviation Group was largely inspired by Mr. S. W. G. Foster, an Associate Fellow of the Society and a design consultant. The Group expects to take an active part in the International Agricultural Aviation Conference which is to be held at Cranfield in September. The Agricultural Aviation Group is the second group to be formed within the Society since the Council agreed to the formation of groups to cover small specialized fields of aeronautics. An indication of the wide range of the interests of members of the Society is given by the fact that the Society now has an Astronautics and Guided Flight Section, a Man-Powered Aircraft Group, an Agricultural Aviation Group, and, within the next month or two, will also have a Historical Group.

\section{Efficient Use of Man-power in Industry}

The report of an inquiry undertaken by the National Joint Advisory Council into practices impeding the full and efficient use of man-power has now been published by the Ministry of Labour and National Service (pp. 16. London : H.M. Stationery Office, 1959. ls. net). The inquiry was concerned with restrictive labour practices, and the Council considers that the results of the inquiry are encouraging. Some 64 industries reported that they had no problems in regard to the efficient use of manpower and a further 42 had set up machinery to deal with any such problems or appeared to be establishing such machinery. Six industries needed more time, or because of various difficulties had been unable to make a joint examination, though some of these industries are of considerable importance in the national economy, and the Council expresses concern about the position in this group. In the ship-building and ship-repairing industry there are problems which need to be tackled if greater efficiency is to be achieved and this calls for efforts from both employers and trades unions. More generally, the report points out that much depends on the use to which joint machinery is put, but the existence of an organization for joint consultation and the fact that such organization functions will afford some grounds for both hope and confidence.

\section{Tyneside Association of Libraries for Industry and} Commerce

THe Tyneside Association of Libraries for Industry and Commerce was formed last September under the sponsorship of the Northern Regional Board for Industry, the Tyneside Productivity Committee, and the North East Industrial and Development Association. Having its headquarters at the Commercial and Technical Department of the Central Library, New Bridge Street, Newcastle upon Tyne 1, the main purpose of the Association is the co-ordination and development of existing facilities in the Tyneside area in order "to help industry and commerce by making information readily and quickly available". Use of the service is available to any one free of charge; membership is open to any firm or organization which maintains a library and/or information department, and is willing to supply non-confidential information on request. To reduce the burden on headquarters, the brochure describing the service suggests that inquiries should, in the irst place, be directed to the nearest public library; if that fails (or if the matter is urgent) the inquiry may be sent direct to the Association's headquarters. The chairman of the Association is R. A. Cookson, vice-chairman of the Northern Regional Board for Industry. The honorary secretary is the Newcastle City Librarian, from whom copies of the brochure may be obtained.

\section{Chemical Control of Eelworms on Strawberries}

THE effectiveness of chemical substances in the control of the several eelworms which infest strawberries has been examined and discussed by $R$. S. Pitcher (J.Hort. Sci., 34, No. 2 ; 1959). Although the hot-water treatment gives a satisfactory control of eelworm, it has several disadvantages, notably that it is time-consuming, exacting, and requires precision, and it cannot be used in the field on an already established and growing crop. Hence the desirability of discovering chemical methods of control. In the present investigation, a number of nematicides were tested under pot conditions and field trials were carried out with parathion. All treatments rapidly reduced the symptoms caused by the three eelworm species, but the persistence of the remedial effect varied according to the kind of infestation involved. Pre-planting dips were consistently more effective than spraying of established plants in the field. With each of the three eelworm species, the level of infestation was greatly reduced by parathion $(0 \cdot 1$ per cent of active ingredient), whether used as a drench, spray, or pre-planting dip.

\section{Non-Cartridge Type Demineralized Water Units}

WATER demineralizing, or de-ionizing, units are now superseding the still and distilled water delivered in carboys as a source of supply of purified water for laboratories and similar establishments. A feature of many such units, however, is their reliance on detachable cartridges of ion exchange resins which are returned to the supplier when exhausted. The Mark 4 and Mark 5 Portable "Deminrolit" plants manufactured by the Permutit Co., Ltd., Gunnersbury Avenue, London, W.4, have been designed for easy 'on the spot' regeneration of the exhausted ion exchange material, thus obviating the need for detachable cartridges and replacements. Both plants consist of a pair of sealed columns charged respectively with "Zeo-Karb" cation and "DeAcidite" anion exchange resins, the water being passed through the columns in that order. Flexible connexion and delivery tubes, with a multi-valve control system, facilitate operation and regeneration. A built-in dial-type conductivity tester enables 'spot' checks to be made on the quality of water being produced. By this means the point at which regeneration becomes due may be determined precisely. Regeneration involves flushing the cation column with a dilute solution of hydrochloric acid and the anion column with dilute caustic soda or soda ash solution. Both columns are then rinsed with water, when the plant is ready for further use. Both plants are constructed throughout from noncorrodible materials and operate at normal cold water tap temperatures and pressures. 